\title{
MODELAGEM DE PROCESSOS EM BIBLIOTECAS UNIVERSITÁRIAS: APLICAÇÕES EM SERVIÇOS DE ATENDIMENTO
}

\author{
ARNALDO ALVES FERREIRA JÚNIOR* \\ ANTONIO PEDRO CASTRO MOTA**
}

\begin{abstract}
RESUMO
A pesquisa tem por objetivo analisar os processos dos serviços oferecidos pelo Sistema de Bibliotecas/SIBI, da Universidade Federal de Goiás/UFG, especificamente, o serviço de quitação de multas e o de empréstimos entre bibliotecas. Fez-se uma revisão de literatura, contextualizando a pesquisa e abordando os principais conceitos pertinentes. A metodologia adotada é classificada como de natureza aplicada, pois tem como objetivo gerar conhecimentos para auxiliar a solução de problemas específicos. A análise completa foi desenvolvida por meio da identificação, mapeamento e modelagem dos processos citados. Concluiu-se, a partir destas considerações, que a gestão por processos é de fundamental importância na gestão de qualquer organização.
\end{abstract}

PALAVRAS-CHAVE: Gestão por Processos. Gestão de Processos. Bibliotecas Universitárias. Serviços de Atendimento.

\section{PROCESS MODELING IN UNIVERSITY LIBRARIES: APPLICATIONS IN SERVICES SERVICE}

\begin{abstract}
The research aims to analyze the processes of the services offered by the Library System / SIBI, Federal University of Goiás / UFG, specifically the service of discharge of fines and the loan between libraries. A literature review is carried out contextualizing the research and addressing the main pertinent concepts. The adopted methodology is classified as an applied nature, since it aims to generate knowledge to help solve specific problems. The complete analysis was developed through the identification, mapping and modeling of the mentioned processes. It is concluded from these
\end{abstract}

Doutor em Ciência da Informação. Professor Adjunto do Curso de Gestão da Informação da Universidade Federal de Goiás. ajunior78@gmail.com

** Graduação em andamento em Gestão da Informação na Universidade Federal de Goiás. antoniopedro.castromota4@gmail.com 
considerations that the management by processes is of fundamental importance in the management of any organization.

KEY WORDS: Process Management. Processes management. University Libraries. Cares services.

\section{INTRODUÇÃO}

A informação é um elemento essencial para quase tudo que uma organização faz. Sem o entendimento dos processos organizacionais e humanos, em que as informações se transformam em conhecimento, percepção e ação, as empresas tornam-se incapazes de compreender a importância das fontes e tecnologias de informação. As organizações vivem num ambiente incerto, e usam as informações para dar sentido às mudanças do ambiente externo. Elas organizam e processam informação para gerar conhecimento, e as avaliam para tomada de decisões (CHOO, 2003).

De acordo com CBOK 3.0 (G.uia para o Gerenciamento de Processos de Negócio), a definição de processos consiste em "uma agregação de atividades e comportamentos executados por humanos ou máquinas para alcançar um ou mais resultados" (2013, p. 35). Os processos são compostos por várias tarefas ou atividades inter-relacionadas com o objetivo de resolver questões específicas, porém consomem recursos como tempo, dinheiro e materiais (ABPMP, 2009).

Para Pavani Júnior e Scucuglia, (2011, p. 113), "processo é o título dado a uma série de atividades/objetivos, transformando entradas (inputs) em saídas/produtos (outputs)", de modo a atribuir às ações da organização determinado grau (tangível) de agregação de valor.

Para ABPMP (2009), Processo de negócio:

é um conjunto de atividades independentes, ordenados no tempo e espaço de forma encadeada, que ocorre como resposta a estímulos (eventos) e que possui um objetivo, início, fim, entradas e saídas bem definidos. Estão ligados diretamente à cadeia de valor, "core business" ou ao negócio principal da organização. É definido como um trabalho ponta-a-ponta que entrega valor aos clientes (ABPMP, 2009, p. 318).

A partir da compreensão de processos, é necessário diferenciar a Gestão de Processos da Gestão por Processos. De maneira simples e direta, pode-se entender a Gestão de Processos como uma realização da melhoria contínua dos processos e a Gestão 
por Processos como realização da análise, modelagem e a implementação dos processos na organização, onde irá mudar sua estrutura. (MOREIRA; MINGATTO; DRUKER, 2010).

Em outras palavras, a Gestão de Processo acontece quando se faz a gestão de um ou mais processos separados, e a Gestão por Processos ocorre quando se faz a gestão ponta a ponta dos processos. Esta última, por sua vez, refere-se a um modelo de gestão baseado em serviços, focado na entrega de valor para o cliente e em que as organizações são dirigidas por processos. Esta perspectiva contrapõe-se à visão tradicional, em que o gerenciamento é hierárquico na delegação de responsabilidades.

Para uma gestão mais eficiente, é fundamental a utilização de gerenciamento de processos. Trata-se de um "conjunto definido de atividades e comportamentos realizados por humanos ou máquinas para atingir uma ou mais metas". (PAVANI JÚNIOR; SCUCUGLIA, 2011, p. 113). Além disso, pode trazer possíveis soluções, como o pensamento $l e a n^{1}$, que objetiva melhorar a produtividade dos pontos de gargalos, minimizar envolvidos no processo, designar atividades, criação de regras e automatização de atividades.

O CBOK (2009) apresenta alguns benefícios e vantagens para diferentes partes interessadas. Esses benefícios são divididos em quatro partes, e devem ser vistos de diferentes formas, de acordo com a maturidade da organização.

- Benefícios para a organização: a transformação de processos requer definições claras de responsabilidade e propriedade, bem como visibilidade, entendimento e prontidão para mudanças, o que aumentam a sua agilidade, por fim a avaliação de custos de processos facilita o controle e a redução de custos;

- Benefícios para o cliente: os colaboradores atendem às expectativas de partes interessadas; o compromisso com clientes é melhor controlado;

- Gerência: o aperfeiçoamento do planejamento e suas projeções; a otimização no desempenho ao longo do processo;

\footnotetext{
${ }^{1}$ Pensamento Lean pode ser entendido como um sistema de gestão e também uma estratégia de negócios voltada exclusivamente para aumentar a satisfação dos clientes. Sua essência é a capacidade de eliminar desperdícios continuamente e resolver problemas de maneira sistemática. Isso implica repensar a maneira como se lidera, gerencia e desenvolve pessoas. O pensamento Lean possui cinco princípios que devem ser considerados na seguinte sequência: Valor, Fluxo de Valor, Fluxo Contínuo, Produção Puxada, Perfeição.
} 
- Ator de processo: maior segurança a ciência sobre seus papéis e responsabilidades; maior contribuição para os resultados da organização e por consequência, maior possibilidade de visibilidade e reconhecimento pelo trabalho que realiza.

O campo de pesquisa/unidade escolhida para fazer esse mapeamento de processo foi o sistema de bibliotecas (SIBI) da Universidade Federal de Goiás (UFG), pois, foi observado que esta estrutura de serviços apresenta um conjunto de processos passíveis de mapeamento. E, por possuir vários setores que oferecem diversos produtos e serviços, percebe-se uma necessidade de integração das áreas. Tal mapeamento poderá trazer maiores percepções da estrutura dos serviços prestados, e em decorrência disso, possibilitar ao gestor melhores condições de administrar a oferta de tais serviços.

Assim, para orientar o desenvolvimento deste trabalho, e considerando a aplicação de modelagem de processos aos serviços de atendimento em Bibliotecas Universitárias, buscou-se saber quais as melhorias que poderiam ser implementadas ao se mapear tais serviços, com o auxílio da Gestão por Processos. Para isso, organizou-se os objetivos deste trabalho, que consistiram em analisar os processos dos serviços oferecido pelo Sistema de Bibliotecas (SIBI), da Universidade Federal de Goiás (UFG). Especificamente, focou-se no serviço de pagamento de multas e empréstimos entre bibliotecas do sistema:

- Identificar os serviços oferecidos pelo SIBI/UFG;

- Mapear e Modelar os processos dos serviços de Pagamento de Multas e de Empréstimos entre bibliotecas, oferecidos pelo SIBI da UFG, identificando falhas;

- Redesenhar tais processos, propondo melhorias e indicando sugestões de automatização, conforme cada caso.

\section{METODOLOGIA}

As bibliotecas universitárias oferecem apoio às atividades de ensino, pesquisa e extensão. O sistema de bibliotecas da UFG busca desempenhar o papel de disseminador de informação e centro de pesquisa para a sociedade. É também gestor de conhecimento produzido na universidade, o qual fica disponibilizado por meio da Biblioteca Digital de Teses e Dissertações (BDTD), do Portal de Periódicos da UFG e do Repositório Institucional (RI). Seus acervos 
são abertos a qualquer pessoa, para consulta, bem como seus espaços de estudo pode ser utilizados por quem tenha interesse.

A Biblioteca Central foi criada em 24 de agosto de 1973, com a junção de 13 bibliotecas departamentais, reunindo os acervos no mesmo prédio na faculdade de Direito. Assim, surgiu a primeira unidade do SIBI/UFG, a Biblioteca Central (BC). De acordo com o seu site, por volta do "final da década de 1980 um acordo da UFG com o Ministério da Educação possibilitou a construção de um prédio específico para a biblioteca no Campus Samambaia". A partir disso, a Biblioteca Central foi transferida, em 1989, para o mesmo.

A biblioteca oferece diversos serviços, entre eles: Capacitação de usuários, Laboratórios de Informática, Levantamento de acervo, Catalogação na Fonte, Empréstimo Entre Bibliotecas e Negociação de multas. Alguns são restritos para comunidade UFG, como o que será objeto desta pesquisa: o de empréstimo entre bibliotecas e negociação de multas.

\subsection{Procedimentos metodológicos} SIBI/UFG.

Para a seleção dos processos a serem trabalhados, exige-se uma percepção clara dos objetivos da organização/instituição. Para isso, a seleção dos processos foi feita por meio de análises referentes à avaliação de impacto/importância sobre as demandas de serviços oferecidos pela biblioteca, e avaliação da pertinência de desempenho das atividades relacionadas ao processo, na ordem abaixo:

- Levantamento e análise de documentos;

- Listagem de processos;

- Entrevista com Bibliotecária/participantes do processo;

- Reajuste de listagem de processos;

- Seleção dos processos.

Objetivo Específico 2: Mapear e Modelar os processos dos serviços de Pagamento de Multas e Empréstimos entre bibliotecas, oferecidos pelo SIBI da UFG, identificando falhas.

A modelagem de processos foi feita a partir do mapeamento das atividades. Este mapeamento foi realizado por meio de análise de documentos relacionados aos processos e entrevistas com os envolvidos no processo. $O$ sequenciamento das atividades 
ou modelagem foi feito utilizando-se o software Bizagi Modeler². Seguem ações desempenhadas nesta etapa:

- Identificação das atividades;

- Sequenciamento de atividades;

- Inserção do sequenciamento de atividades na ferramenta Bizagi.

Objetivo específico 3: Redesenhar tais processos, propondo melhorias e indicando sugestões de automatização, conforme cada caso.

A partir dos processos modelados, possibilitando uma visão geral, foi realizada uma análise, tendo como objetivo identificar falhas. Como apoio à análise dos resultados, foi utilizada a técnica Brainstorming, que é uma dinâmica de grupo, que tem como objetivo explorar a potencialidade criativa de um indivíduo ou de um grupo. Com isso, foram identificados diversos pontos de melhorias, que foram desenhados utilizando a ferramenta Bizagi, na ordem a seguir:

- Análise dos processos;

- Redesenho do processo.

\section{REFERENCIAL TEÓRICO}

Esta seção tem por finalidade apresentar o referencial teórico para a pesquisa, expondo conceitos e definições relacionados ao tema, baseados em autores especialistas na área. Serão apresentadas definições de Processo, Gestão de Processo e Gestão por Processo, assim como, conceitos essenciais para a compreensão da presente pesquisa.

\subsection{Gestão de processos}

$\mathrm{Na}$ realização de atividades diárias, as pessoas têm a necessidade de organizar e planejar suas tarefas. A sua realização sempre passa por algum processo para que tenham uma estrutura de organização mínima. Assim, percebe-se que a quantidade de processos realizados, diariamente, em atividades de trabalho e lazer, é bastante grande. E, por sua vez, tais processos requerem mecanismos estruturados de gestão para que possam ser realizados

${ }^{2}$ Bizagi Modeler é um software gratuito, desenvolvido pela empresa BIZAGI, com o objetivo de fazer modelagem descritiva, analítica e de execução, de processos de negócio utilizando a notação BPMN de acordo com toda a disciplina de BPM. 
de maneira lógica e eficiente. Nesse contexto, utiliza-se a Gestão de Processos, a qual será apresentada a seguir.

Gestão de processos "é considerada por alguns autores como uma forma de apoio ao progresso gerencial na busca por melhores resultados". (ASSUNÇÃO; MENDES, 2000 apud CONSELHO NACIONAL DO MINISTÉRIO PÚBLICO, 2013, p. 3). Nessa perspectiva, Falcão Júnior; Santos (2016.) apresentam que sua característica é:

um recurso gerencial importante na busca por eficiência na operacionalização dos serviços públicos, por visar às melhores formas de trabalhar e aumentar a qualidade nos serviços prestados à população. Subjacente à operação de qualquer processo circula um fluxo de informações, permeando todas as suas etapas, transferindo informações nos dois sentidos e em todos os elos. (p. 7)

Na sua visão, Anjos (2016, p. 187) afirma que o conceito de Gestão de Processos não é um assunto novo, mas:

em grande parte das organizações, ele ressurge como uma ferramenta ou disciplina, [...], na eterna busca da eficácia e eficiência da gestão, visando a melhoria dos resultados e a satisfação dos clientes. (ANJOS, 2016, p. 4 apud PAIM, CAULLIRAUX; CARDOSO, 2007)

Os autores apresentam como "um conjunto articulado de tarefas permanentes para projetar e promover o funcionamento e aprendizado sobre os processos". Anjos (2016, p.187 apud PAIM et al. 2009, p.112) afirma, também, que ela é "centrada em melhorar, redesenhar, e automatizar processos, seguindo uma lógica de promover mudanças no negócio".

\subsection{Gestão por processos}

$\mathrm{Na}$ execução das rotinas de trabalho, as organizações tradicionais utilizam o gerenciamento hierárquico na delegação de responsabilidades de um nível mais alto da empresa para o nível imediatamente inferior, com prestação de contas final, atribuída às partes interessadas dessa mesma organização. Essa delegação é demonstrada como um foco gerencial de cima para baixo (CBOK 3.0, 2013). Ao contrário, nas organizações dirigidas por processos, a responsabilização é horizontal e focada na entrega de valor para o cliente. Desse modo, as organizações dirigidas por processos trabalham com seus desenhos, documentação, medição e transformação. 
De acordo com o BPM CBOK 3.0, uma organização, para ser orientada por processos, não significa que estes sejam sua única forma de gerenciamento, medição de desempenho ou estruturação organizacional. Outras medições de desempenho continuam sendo importantes, como as capacidades funcionais e relacionadas a produtos ou serviços.

Para atingir sempre um melhor desempenho, uma organização deve levar em conta sua estrutura como um todo e a definição dos processos e responsabilidades nos seus diversos níveis de gestão. Assim, é importante destacar que, na gestão por processos, é fundamental as estruturas funcionais, pois são elas que suportam a execução de todos os processos funcionais e produtivos.

A gestão por processo (Business Process Management BPM) consiste, principalmente, na quebra desse paradigma funcional. A partir disso, propõe-se uma visão interfuncional de como os processos ponta a ponta ${ }^{3}$ poderiam ser mais bem geridos, visando eliminar os efeitos que prejudicam esses conflitos internos. Trata-se, basicamente, de uma mudança na maneira de gerenciamento da organização e dos seus líderes. (PAVANI JÚNIOR E SCUCUGLIA, 2011).

De acordo com Pavani Júnior e Scucuglia (2011, p.103), o:

BPM é uma disciplina que visa inverter a lógica de gestão para um ponto de vista focado na cadeia de agregação de valor funcional em que os interesses do processo que sobrepujar interesses departamentais.

Então, muito mais do que mapear e melhorar processos, o BPM altera, significativamente, o modo como a cadeia de valor é encarada. O Ministério Público Federal (MPF, 2013) conceitua a Gestão por Processos, ou Business Process Management (BPM), como uma "abordagem sistemática de gestão que trata de processos de negócios como ativos, [...], primando pela excelência organizacional e agilidade nos negócios". Visão que pode ser complementada como,

\footnotetext{
${ }^{3}$ Processos ponta a ponta tratam-se de uma visão global da organização, além disso busca interpretar como cada pedacinho do processo se relaciona com todos os outros, para estabelecer um fluxo que vai agregando valor conforme é executado, e que não depende de uma pessoa ou um departamento específico para ser concluído. Esses pedacinhos são as tarefas e as atividades que precisam ser executadas para que esse fluxo aconteça.
} 
uma abordagem para identificar, desenhar, executar, documentar, medir, monitorar e controlar de forma automatizada ou não, processos de negócio para uma realização coerente, orientada para resultados e alinhada com os objetivos estratégicos da organização. (ASSOCIATION OF BUSINESS PROCESS MANAGEMENT PROFESSIONALS, 2008 apud PRADO JÚNIOR, 2013, p. 18-19).

E Rosemann e Bruin (2005) colaboram para consolidação do entendimento deste conceito, afirmando que a Gestão por processos:

pode ser entendida como uma prática de gestão organizacional holística, que exige compreensão e envolvimento da alta administração e uma cultura receptiva aos processos de negócio. É baseada em uma arquitetura de processo, que capta o inter-relacionamento entre os principais processos empresariais e que permite o alinhamento com as estratégias, metas e políticas de uma organização. (apud MOREIRA; MINGATTO; DRUKER, 2010).

Quando se trata de gerenciamento por processos, uma ferramenta básica, porém, importante é a modelagem dos processos. Trata-se da representação gráfica do sequenciamento das atividades apresentadas de maneira clara e objetiva. Essas representações apresentarão o funcionamento básico dos processos. O BPM CBOK V3.0 (2013) define a modelagem de processos como um conjunto de atividades envolvidas na criação de representações de negócios existentes ou propostos. É um mecanismo utilizado para relatar a situação atual e descrever a visão futura dos processos de negócios.

Um termo que causa confusão de terminologia é "desenho" de processos, pois quando dele falamos, estamos nos referindo à criação de novos processos. A modelagem, por sua vez, é o ato de representar graficamente as atividades diferentes ao desenho, que é o ato de definir novas peculiaridade/especificidade ao processo.

O objetivo da modelagem é representar um processo a ponto de ser compreensível pelas partes interessadas, pelos gerentes e executivos, pelo pessoal de programação de sistemas, passando pelos donos de processo e pelos próprios analistas. Essa representação deve ser feita através de mapas, fluxos ou diagramas.

De acordo com Pavani Junior e Scucuglia (2011), existe uma confusão de conceitos acerca da noção de mapeamento de processos e de gestão por processos. O mapeamento de processos refere-se ao levantamento de informações, o entendimento da lógica inserida na cadeia de informações até a modelagem. 
Já a otimização do trabalho, alinhada a outras práticas de controle e acompanhamento refere-se a Gestão por Processo. assim, o mapeamento é a primeira etapa a ser feita para, posteriormente, realizar-se a implementação da Gestão por Processo.

É importante que a atividade de mapeamento seja bem feita, pois este é o levantamento das informações determinantes para a compreensão e futura tomada de decisão na melhoria dos processos. Isso porque, um processo mal mapeado resulta em informações inadequadas, compressões erradas e, posteriormente uma tomada de decisão desestruturada. (PAVANI JUNIOR E SCUCUGLIA (2011). A figura 1, a seguir, ilustra o ciclo de vida da gestão por processos:

Figura 1 - Ciclo de Vida da Gestão por Processos

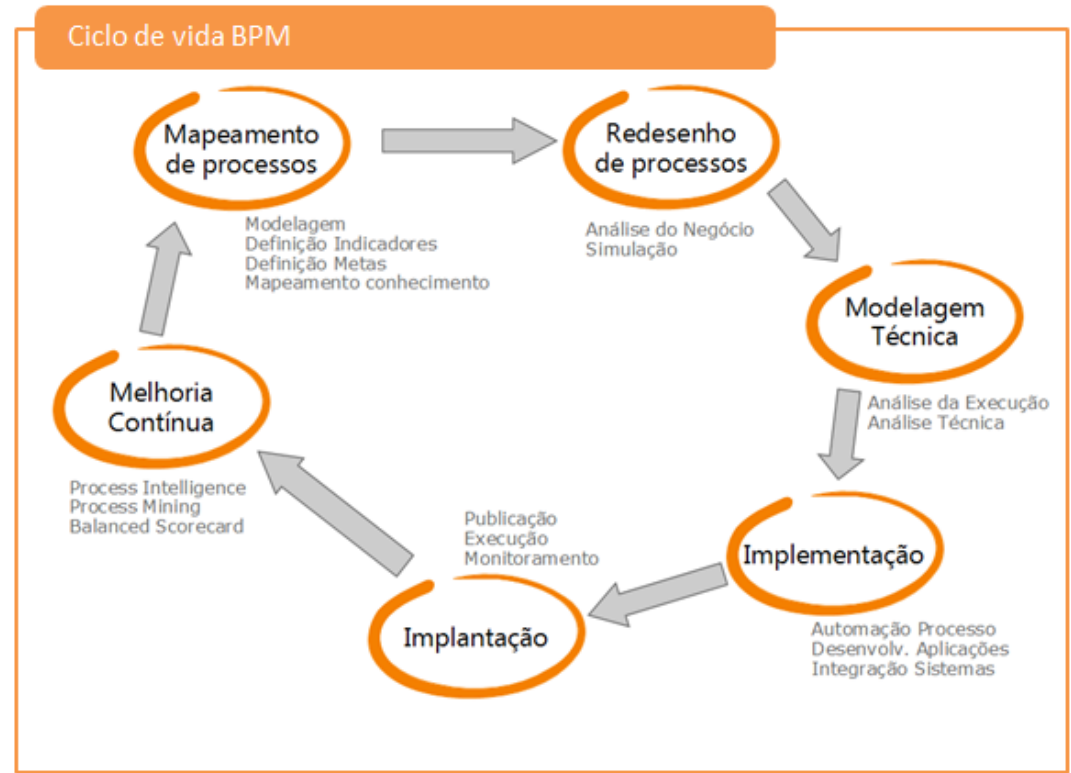

FONTE: Blog iProcess. Disponível em: <http://blog.iprocess.com.br/2012/04/um-bpmnpara-cada-proposito-de-modelagem-de-processos/>. Acesso em: 15. nov. 2017.

O tema Gestão por Processos, apesar de novo, está se espalhando ao redor do mundo, isto pois esta já foi aplicada e teve benefícios comprovados em diversas organizações. Pavani Junior e Scucuglia (2011), afirmam que "não faltam casos de sucesso. Logicamente essa mudança filosófica é apenas a ponta do iceberg." Com isso, o BPM CBOK (2009) aponta nove áreas 
essenciais para uma aplicação de bem-sucedida da Gestão por Processos, entre elas: o Gerenciamento, a Modelagem, a Análise, o Desenho, o Gerenciamento Do Desempenho, a Transformação, a Organização, os Processos Corporativos e as Tecnologias, conforme figura 2 , a seguir:

Figura 2 - Nove Áreas do Conhecimento da Gestão por Processos.

$$
\text { BPM - Áreas de Conhecimento (CBOK) }
$$

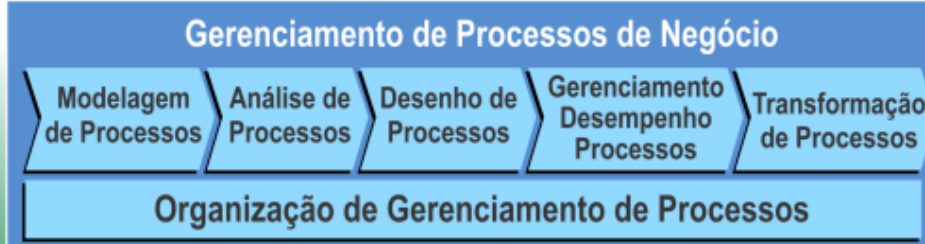

Gerenciamento de Processos Corporativos

\section{Tecnologias de Gerenciamento de Processos de Negócio}

FONTE: BPM CBOK (2009). [Adaptado].

É importante destacar que, ao adotar cada uma dessas áreas de maneira excelente, a organização alcança resultados concretos e objetivos. Como Pavani Junior e Scucuglia (2011) bem afirmam: "esta é a intenção final dos profissionais de processos: estudar os impactos destes paradigmas e alavancar eficiência, eficácia e resultados sistemáticos à gestão das organizações".

Contudo, é importante lembrar alguns passos para uma boa Gestão por Processos, entre eles: o Pensamento lean, a Padronização dos processos e a Automatização. Estes passos serão esmiuçados a seguir:

- Pensamento lean: O Pensamento lean pode ser entendido como um sistema de gestão e também uma estratégia voltada exclusivamente para aumentar a satisfação dos clientes. Seu objetivo é eliminar desperdícios continuamente e resolver problemas de maneira sistemática.

Padronização dos processos: Pavani Junior e Scucuglia (2011) falam que, se os processos apresentam muitas variações, é por que derivam de procedimentos não padronizados. 
Se cada profissional executa suas tarefas de um modo, então a soma de diferentes níveis de habilidades resultara em instabilidade. Padronizar processos formalizados as ações daqueles com melhores resultados é uma das principais atividades a serem realizadas para confiabilidade e estabilidade processual (p.119).

Ou seja, se a variação dos processos é pouca, fica mais fácil de controlar a instabilidade.

- Automatização: De acordo com Pavani Junior e Scucuglia (2011), a automação de processos está se tornando cada vez mais importante, principalmente para coordenar grumos separados. Assim, "a automação reduz tempo e custos, reduz defasagens de tempo e age como um assistente e esforços humanos (mais eficiente)" (p. 106). Porém, automatizar o AS-IS ${ }^{4}$ é um dos maiores erros e mais prejudiciais que podemos cometer em BPM. Pavani Junior e Scucuglia (2011) apud ABPMP (2009, p. 106), afirmam que:

Uma das piores coisas que a organização pode fazer é tomar o modelo AS-IS e colocar tecnologia da informação em cima. É ruim por duas razões: primeiro, a tecnologia da informação pode ser cara. Pode haver soluções baratas e igualmente efetivas, tais como redesenho de processos ou treinamento. Segundo, apesar do investimento, o problema pode não ser resolvido, e automatizá-lo pode ainda piorar a situação (p. 120).

Para uma boa gestão, primeiro deve-se analisar o processo e, depois realizar a modelagem TO-BE ${ }^{5}$. A partir disso, é preciso propor alternativas de automatização. Caso contrário, pode-se correr o risco de automatizar um processo ineficaz (PAVANI JUNIOR E SCUCUGLIA, 2011).

\subsubsection{Gestão de Processos em Bibliotecas}

Os Gestores procuram soluções para sempre melhorar os serviços qualitativos, os ativos e os serviços de informações. Reis e Blattmann (2004) fazem uma pergunta, que vem seguindo esse processo de inserção de novas tecnologias "como gerenciar produtos e serviços de informação?", logo, Reis e Blattmann (2004) falam que:

\footnotetext{
${ }^{4}$ AS-IS é a visão dos processos atuais de uma organização, mostra como esta organização realiza suas atividades em um determinado momento.

5 TO-BE é a visão dos processos futuros de uma organização, mostra a melhor forma de realizar o processo.
} 
[...] em primeiro plano, estabelecer uma cultura organizacional adequada para incrementar técnicas de planejamento estratégico, gerencial e operacional para entender as causas, os impactos, as características, as consequências e as dimensões que envolvem o processo (REIS; BLATTMANN, 2004, p.12).

Posto isto, Santos, et. al. (2003), apontam ser possível fazer o mapeamento dos processos, pois isso trará uma visão por completo das prestações de serviços e produtos de informação oferecidos. Além disso, auxiliará tanto para o planejamento de novos serviços quanto para a análise de processos envolvidos nestes, já em funcionamentos existentes.

A incorporação de novas tecnologias no ambiente de bibliotecas pode alterar os processos administrativos, técnicos e até mesmo os operacionais. Essas alterações precisam ser acompanhadas, pois há a necessidade de compreender as mudanças, de modo que estas possam dar caminho para a gestão da informação. (REIS E BLATTMANN, 2004).

Por conseguinte, a gestão por processos em bibliotecas tem se tornado um instrumento significante no processo de melhoria na qualidade dos processos e serviços oferecidos. Ao analisar os processos da biblioteca central da Universidade Federal de Goiás, foi identificado que existem diversos processos e subprocessos, que influenciam diretamente na qualidade dos serviços prestados como os processos de empréstimo entre bibliotecas e negociação de multas, que foram utilizados para o desenvolvimento deste trabalho.

De acordo com Reis e Blattmann (2004):

[...] [ao se] estudar a gestão por processos em bibliotecas, surge a questão sobre eficácia, ou seja, qual o propósito das bibliotecas no atendimento aos usuários? A princípio trata-se em atender quais são as necessidades de informação de sua comunidade a qual oferece seus produtos e serviços de informação. (p.11)

E completam afirmando:

Isso requer um bibliotecário preocupado em como satisfazer com eficiência e eficácia as necessidades de informação dos usuários. Para isso, busca oferecer um serviço de qualidade com a agregação de valor, gerenciando seus processos com o foco no usuário/leitor. (REIS; BLATTMANN, 2004, p.11) 
Ainda seguindo essa perspectiva, Reis e Blattmann (2004, p. 11) mostram que a representação do gerenciamento de processos simplifica "a compreensão em traçar diretrizes na oferta de serviços e produtos aos usuários - leitores". Os autores explicam também que:

não basta saber organizar simplesmente serviços e produtos de informação, estes necessitam atender às exigências do usuário para que se possa buscar o que existe com facilidade no acesso e no uso dessa informação organizada.

\subsection{Serviços de informação do SIBI/UFG}

O Sistema de Bibliotecas ( $\mathrm{SiBi}$ ) da UFG tem como missão:

[...] promover o acesso a serviços e produtos em informação com excelência, que acompanhem as transformações tecnológicas, sociais e culturais, para atender as necessidades e expectativas da UFG em sua estrutura multicampi.

Como se pode perceber, estão exigindo das unidades de informação uma competência cada vez maior na prestação de seus serviços, conhecidos como serviços de informação.

Para Foskett (1969), a função social de um serviço de informação é investigar o que se conhece acerca de determinado assunto e proporcionar ao consulente tanta informação quanto seja necessária, a fim de preencher uma lacuna em seu conhecimento. (FOSKETT, 1969 apud ROZADOS, 2006, p. 52)

Por seu turno, Rozados (2006) citando também Azevedo (2001), identifica-se serviço de informação como:

[...] uma atividade destinada à identificação, aquisição, processamento e transmissão de informação ou dados e ao seu fornecimento num produto de informação. (AZEVEDO, 2001, p. 1 apud ROZADOS, 2006, p. 54).

Silva et al. (2006, p. 1) colocam que:

Visualizar uma biblioteca universitária como uma organização provedora de serviços, requer a compreensão sobre uma estrutura que abrange: definição de estratégia, valor, marketing, qualidade e gestão da produção. 
Assim, eles apresentam uma proposta de modelo de gestão que se baseia nos requisitos principais para o exercício de uma biblioteca universitária. O modelo proposto reúne três funções organizacionais desdobradas em seis elementos: valor de informação, marketing, percepção/satisfação do cliente, ciclo de serviços, gestão da produção e estratégia nos processos (2006, p. 2). Que tem como objetivo:

Orientar os gestores quanto aos princípios básicos da biblioteca, e propiciar aos mesmos uma tomada de decisão em razão da execução dos processos de gestão, visando garantir a continuidade da biblioteca para que possa atender às exigências e necessidades dos usuários. (SILVA; SCHONS; RADOS, 2006, p. 3).

De acordo com Rocha e Gomes, (1993, p. 1) "na sociedade moderna, informação e qualidade, adequadamente utilizadas, constituem vantagens competitivas". Apesar de vários conceitos sobre qualidade, "todos refletem um objetivo comum: a satisfação do cliente, conquista e garantia do mercado" (ROCHA; GOMES, 1993, p. 1). Elas colocam também que nas unidades de informação, um produto desenvolvido para um grupo específico de usuário, pode prostrar-se inadequado ou sem utilidade para outras categorias. Além disso, dentro do próprio grupo existem diferenças culturais que irão influenciar na qualidade percebida do produto/serviço oferecido. Segundo elas, a qualidade será determinada pela característica percebida pelos clientes. (ROCHA; GOMES, 1993, p. 1).

\section{RESULTADOS}

Os resultados do mapeamento, modelagem e análise dos processos de serviços oferecidos pelo Sistema de Bibliotecas da Universidade Federal de Goiás serão apresentados e discutidos a seguir.

\subsection{Resultados alcançados}

É fundamental mapear e modelar processos dentro de uma organização, como posto anteriormente neste trabalho. Para isso, os resultados das entrevistas aplicadas $e$ as análises da documentação levantadas foram transformadas em mapeamento 
dos processos de empréstimos entre bibliotecas e negociação de multas pertinentes à Biblioteca Central da UFG.

A primeira ação realizada foi a identificação de como cada um dos processos definidos se iniciava. De acordo com os serviços apresentados em entrevista realizada com bibliotecária, os processos começavam com uma ação/comunicação do usuário, mais especificamente quando este possuía a necessidade de realizar o empréstimo de um livro que não estava disponível na Biblioteca Central da UFG e/ou precisava negociar uma multa pelas diversas formas oferecidas na biblioteca.

Após esta etapa, foram identificadas todas as atividades desenvolvidas nesses dois processos. Logo em seguida, na mesma entrevista, foram detalhadas todas as tarefas pertinentes às atividades dos processos. Como apresentado anteriormente, para otimizar um processo existente, é preciso ter uma visão ponta a ponta dos processos e gerar um entendimento do seu estado atual e de como ele chega aos seus objetivos. É necessária, ainda, a utilização da análise de processos (BPM CBOK, 2013).

Após a modelagem desses dois processos realizados na biblioteca central da UFG, foi necessária a aplicação de análises sobre esses processos para identificação de melhorias. Estas foram feitas utilizando-se a técnica Brainstorming, como apresentado anteriormente, analisando-se cada atividade pertinente aos processos. Isso porque, entregar um serviço de qualidade e que atenda a todas as necessidades do usuário é de fundamental importância para uma Biblioteca.

Nas bibliotecas da UFG existem três formas de negociar multas, uma delas é a doação de livros da lista elaborada pela Gerência de Atendimento, na qual é oferecido ao usuário uma quantidade de livros aceitos pela biblioteca. Esta tabela possui como objetivo orientar o usuário sobre quais livros comprar/levar para quitar seus débitos com a biblioteca, visto que foi elaborada de acordo a área de atuação do usuário. Contudo, ela serve apenas para orientar o usuário sobre os livros da biblioteca que estejam precisando na respectiva área, pois, assim, este poderá ajudar sua área de conhecimento, trazendo mais livros para o acervo.

A segunda forma de negociação de multas é a doação de livros pessoais do usuário. O processo de verificação da aceitação dos livros é bastante parecido com o anterior, já que a biblioteca analisará a necessidade de ter o livro entregue pelo usuário; após 
isso, será feita uma verificação sobre sua adequação física para o uso da biblioteca; também é consultado o preço do livro em diferentes sites, como: Estante Virtual, Amazon, Livraria Saraiva, entre outros. A biblioteca comunica, então, o usuário, informando-Ihe sobre a aceitação do livro e o valor abatido. Caso o valor seja menor que a multa, o usuário deve renegociar o restante. Na realização desse procedimento, a biblioteca pesquisa o preço do livro em diversos sites, porém se o usuário tiver pago um valor maior e levar o comprovante, o valor abatido será o maior, assim, ajudando-o financeiramente.

A terceira forma de negociação de multas verificada foi o parcelamento. Isso porque, a biblioteca divide o pagamento das multas, levando em consideração as condições financeiras do usuário, porém, prioriza-se que a última parcela seja no mesmo semestre da negociação. Nesse período de parcelamento, o usuário pode fazer novos empréstimos, porém, é preciso que assine um termo se comprometendo a cumprir os prazos. No final de cada semestre, é feita uma verificação de todos os pagamentos e, caso o usuário não pague o parcelamento, no próximo empréstimo este será notificado e terá que renegociar seu débito, conforme figura 3 . 
Figura 3 - Processo de Negociação de Multas.

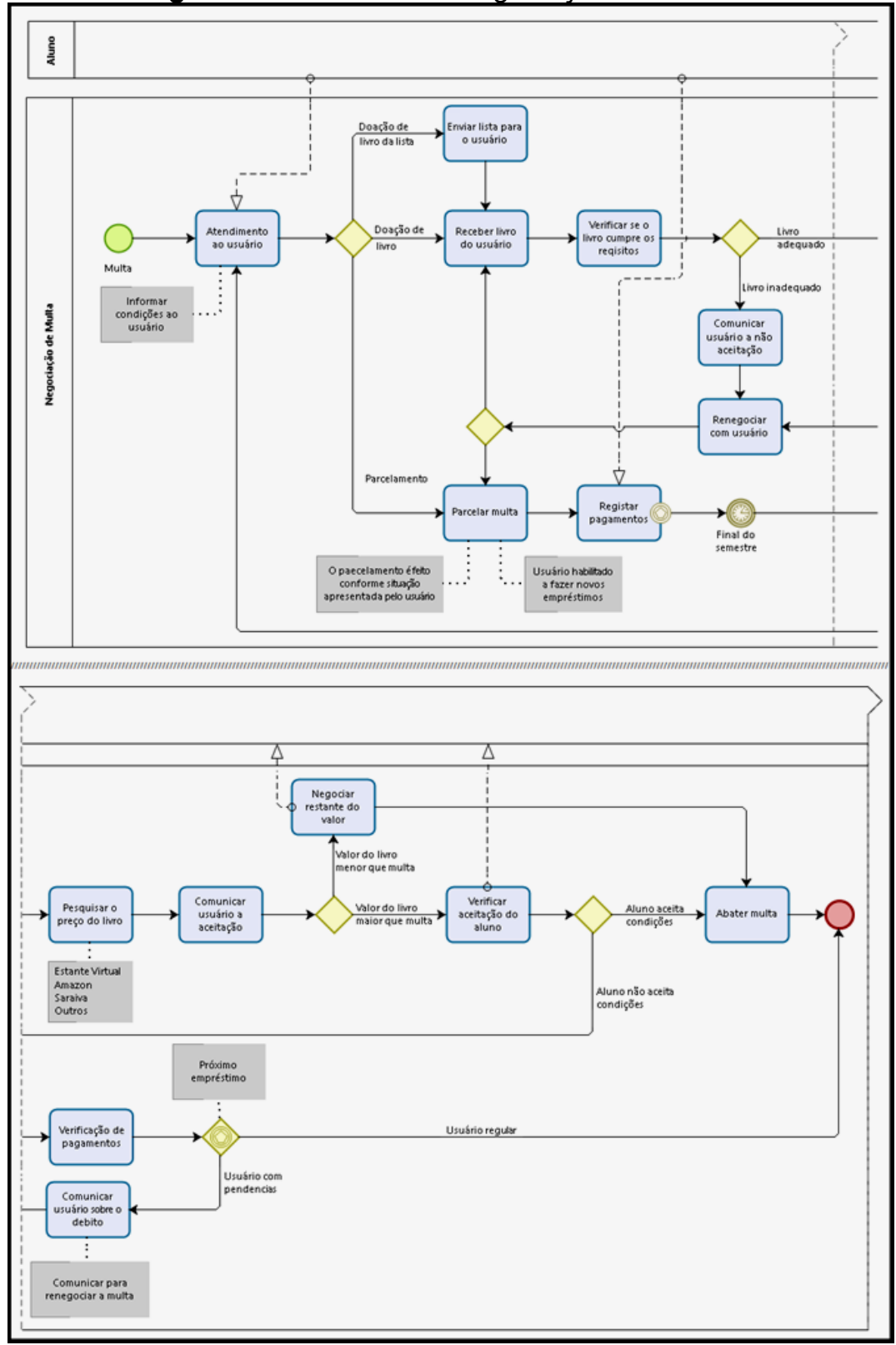

FONTE: Dados da pesquisa. 
Como comentado anteriormente, um usuário pode ter a necessidade de realizar o empréstimo de um livro que não está disponível na biblioteca mais próxima dele. Por este motivo, as bibliotecas da UFG disponibilizam um serviço para alunos de pós-graduação e servidores, que é o Empréstimo Entre Bibliotecas (EEB). Este é disponibilizado aos usuários por dois meses.

O EEB deve ser solicitado via e-mail pelo usuário e pela biblioteca solicitante. A partir do recebimento do e-mail do usuário solicitando um livro, a biblioteca requerente deve encaminhar um e-mail para a biblioteca de origem do material, solicitando-a. Com isso, a biblioteca de origem do material deve verificar e informar a disponibilidade do material, cadastrar o empréstimo no sistema, preparar e enviar o livro. A solicitante deve cadastrar, comunicar e entregar o livro ao usuário. Passando o prazo de dois meses, ao receber o livro, a biblioteca requerente deve cadastrar o seu recebimento, preparar e enviar o livro de volta à biblioteca de origem, onde a solicitada deve cadastrar o recebimento e devolução no sistema, conforme figura 4. 
Figura 4 - Processo de Empréstimo Entre Bibliotecas.

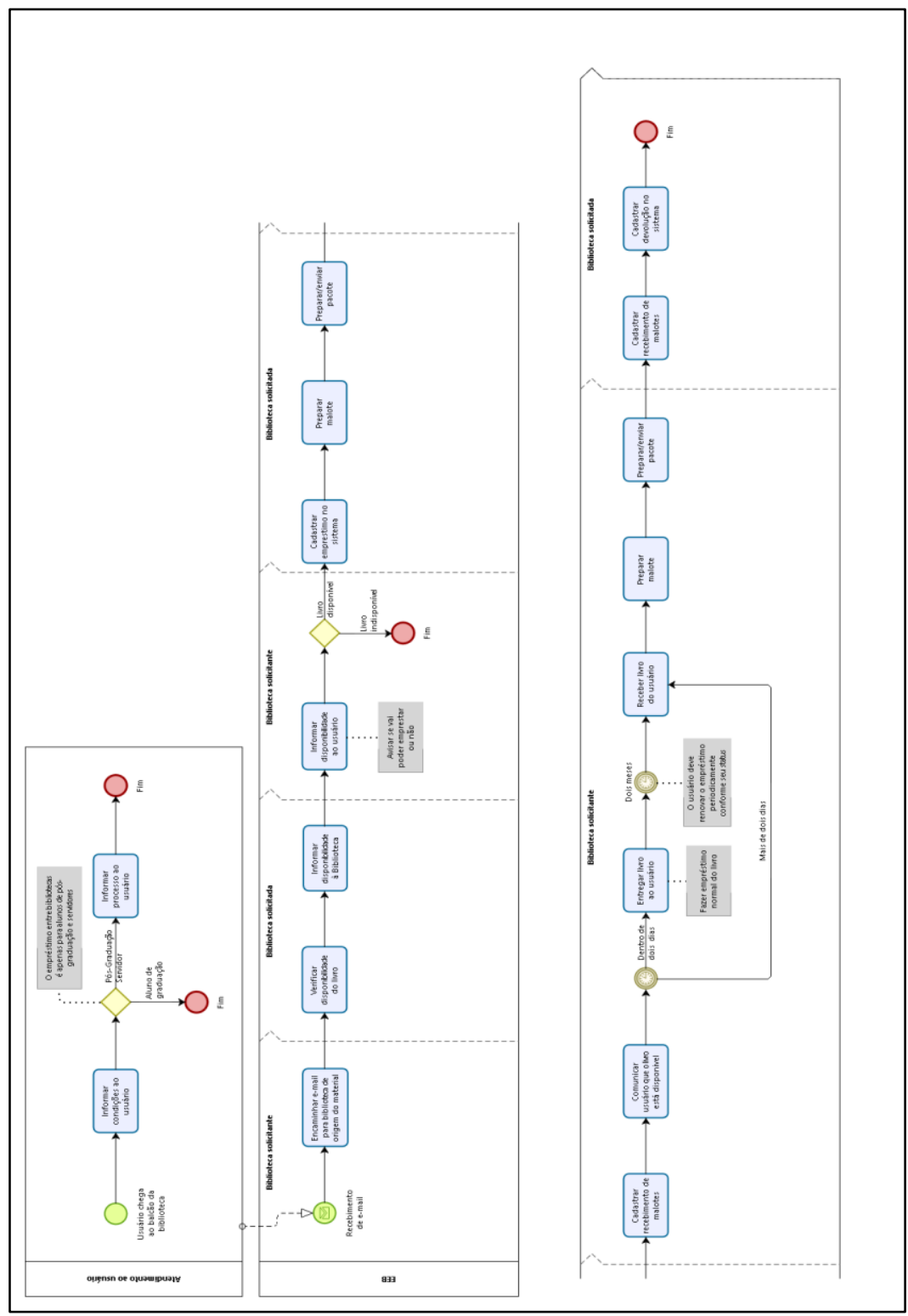

FONTE: Dados da pesquisa 


\subsection{Discussão dos resultados}

Como citado anteriormente, é fundamental mapear, modelar e analisar os processos dentro de uma organização. Contudo, os processos foram mapeados, modelados, analisados e, por fim, sugerida a melhoria nos processos de empréstimos entre bibliotecas e a negociação de multas pertinentes à Biblioteca Central da UFG.

Após o mapeamento e a modelagem, a primeira ação realizada foi a análise, por meio de brainstorming, para, assim identificar as possíveis melhorias. Nas seções de brainstorming, foram apresentadas diferentes/diversas sugestões de melhorais para os dois processos.

A partir dos avanços identificados na modelagem dos processos, foi feita uma segunda análise. Esta foi feita levando em consideração o pensamento lean, que teve como principal objetivo eliminar o retrabalho das atividades. Com isso, foram apresentadas duas sugestões de melhoria, uma para cada processo. Elas poderão trazer benefícios tanto para o usuário quanto para a Biblioteca.

O primeiro processo trabalhado foi a Negociação de Multas, serviço já bem consolidado. Portanto, o mesmo apresenta limitações para implementação de melhorias, devido ao fato de ter que adicionar novos recursos no Sistema de Gestão de Bibliotecas (Sophia). A melhoria sugerida foi "criar função de gestão financeira no Modulo de Atendimento do Sophia", no qual o usuário não terá a necessidade de ir até a biblioteca, levar o comprovante de pagamento de multa. Além disso, não será necessário o envio do comprovante por e-mail para a biblioteca de origem do material. Porém, caso implementada a melhoria sugerida, trará grandes benefícios para os usuários, conforme a figura 5 . 
Figura 5 - Melhorias no Processo de Negociação de Multas.

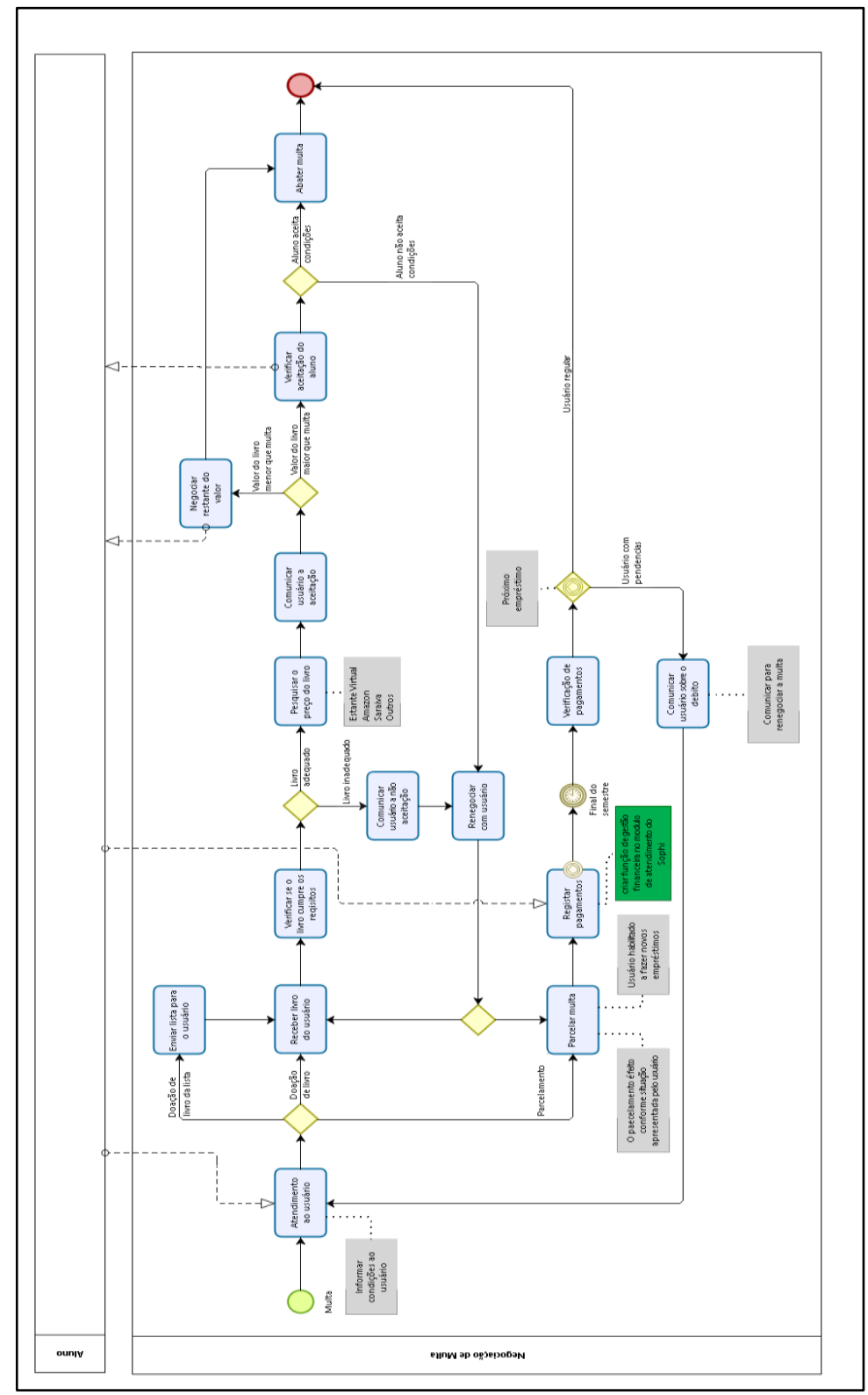

FONTE: Dados da pesquisa. 
O segundo processo trabalhado foi o serviço de Empréstimos entre Bibliotecas. Neste, também foram apresentadas propostas de melhorias, diferentemente do processo de negociação de multas, em que a implementação pode ser feita de maneira simples, apenas modificando políticas e procedimentos. A melhoria sugerida foi em relação ao prazo que o usuário tem para devolver o livro, pois, passado o prazo de dois meses (se o usuário tiver a necessidade de permanecer com o livro, ele poderá ir até a biblioteca solicitar o empréstimo por mais dois meses). Nesta situação, a biblioteca solicita renovação de empréstimo a biblioteca de origem do material, e nesse período, o usuário terá que renovar o empréstimo, periodicamente, conforme seu status. Vejamos o processo na figura 6. 
Figura 6 - Melhorias no Processo de Empréstimo Entre Bibliotecas.

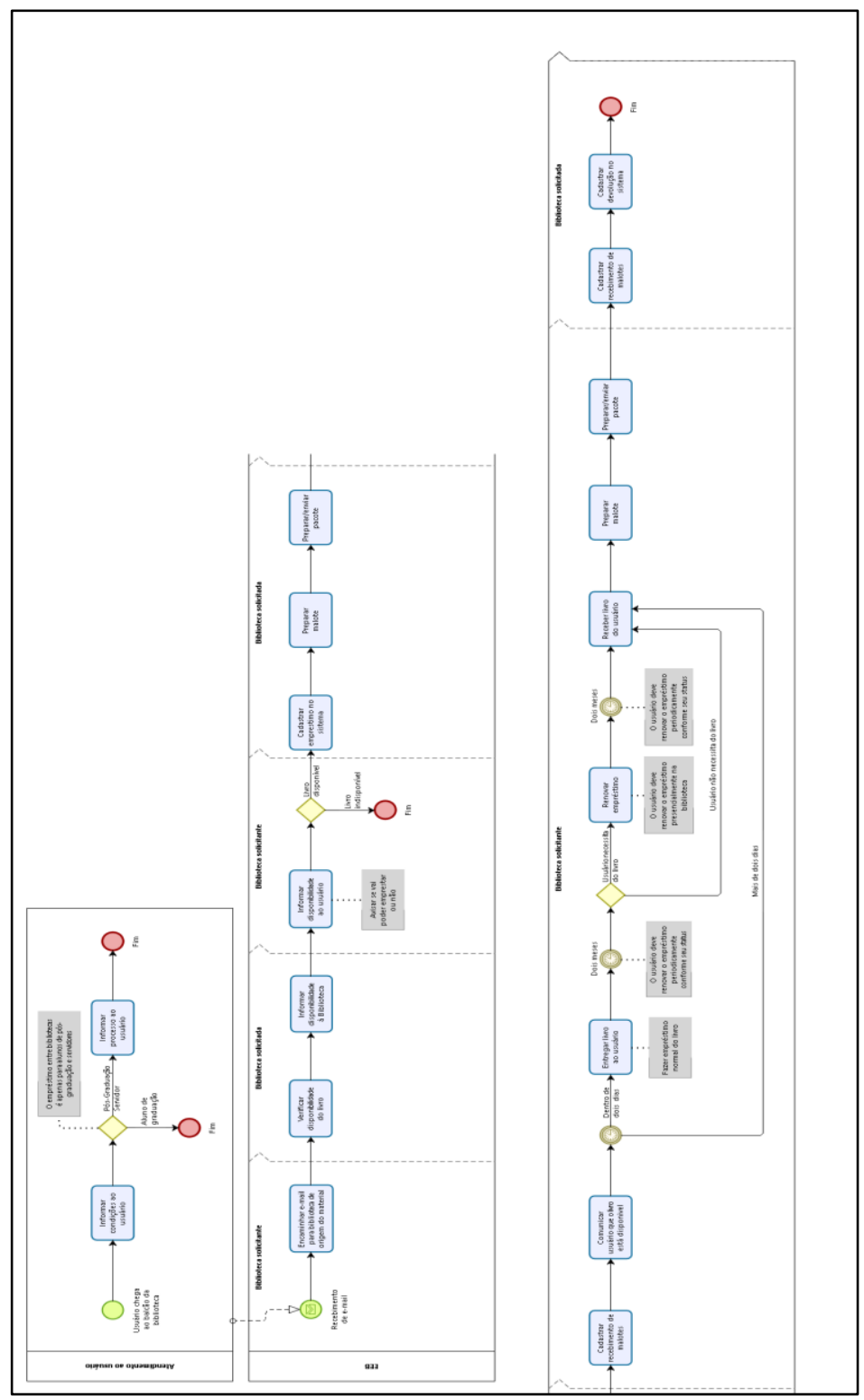

FONTE: Dados da pesquisa. 


\section{CONSIDERAÇÕES FINAIS}

Levando em consideração os aspectos apresentados neste trabalho, foi possível observar a importância da gestão por processos, aplicada a quaisquer organizações. Assim, espera-se que, com esse mapeamento, modelagem e análise dos processos de negociação de multa e empréstimo entre bibliotecas, evite-se, além de trabalho desnecessário, o retrabalho, de modo que se valorize a gestão por processo. Contudo, é importante destacar que a adoção da gestão por processos influenciará a organização como um todo, pois trata-se, basicamente, de uma mudança na maneira de gerenciamento da organização.

O estudo realizado apresentou limitações significantes quanto ao escopo definido. O trabalhado foi aplicado em apenas dois processos, sendo que poderia ter feito o mapeamento das atividades e tarefas, a modelagem e análise ponta a ponta em todos os processos oferecidos pelo sistema de bibliotecas da UFG, assim,trazendo a real gestão por processos para a biblioteca, quebrando os paradigmas funcionais, deste modo, propondo uma visão interfuncional de como os processos ponta a ponta, podendo gerir os processos visando eliminar tarefas e até mesmo atividades.

Em decorrência do tempo disponível, não foi possível mapear, modelar e analisar o processo ponta a ponta. Por este motivo, essas técnicas foram aplicadas apenas nas atividades, deixando as tarefas sem análise. Porém, este trabalho possibilita uma possível continuação em estudos futuros, aplicando-se as técnicas de gestão por processos, juntamente com as estratégias do pensamento lean nas tarefas pertinentes às atividades mapeadas, podendo, assim, ter uma visão ponta a ponta dos processos. Isso possibilitará encontrar diversos pontos de melhorias, permitindo à biblioteca oferecer serviços com maior qualidade para os usuários. Contudo, sugere-se que seja realizado o mapeamento, a modelagem e a análise de todos os processos oferecidos pelo sistema de bibliotecas da UFG, com a implementação da gestão por processos, modificando-se, assim, sua maneira de gerenciamento e seus serviços oferecidos.

\section{REFERÊNCIAS}

ALMEIDA, Jaine Franciele de et al. APLICAÇÃO DA METODOLOGIA MASP AO PROCESSO DE ALTERAÇÃO TÉCNICA DE PRODUTOS EM UMA INDÚSTRIA DE MÉDIO PORTE. Enep, Paraná, p. 1-18, 2014. 
ANJOS, Maylta Brandão dos. Ensino, Pesquisa e Extensão: Reflexões em instituições de ensino e instituições de trabalho. Rio de Janeiro: Agenda Dinâmica Gráfica e Editora, 2016.

ASSOCIATION OF BUSINESS PROCESS MANAGEMENT PROFESSIONALS. BPM CBOK: guia para o Gerenciamento de Processos de Negócio Corpo Comum de Conhecimento ABPMP BPM CBOK V 3.0. Brasil, 2013.

ASSOCIATION OF BUSINESS PROCESS MANAGEMENT PROFESSIONALS. Guia para o Gerenciamento de Processos de Negócio Corpo Comum de Conhecimento (BPM CBOK) Versão 2.0. Brasil, 2009.

BARROS, RJMD et al. Manual de gestão por processos: Secretaria Jurídica e de Documentação Escritório de Processos Organizacionais do MPF. BRASÍLIA: [sn], 2013.

$\mathrm{CHOO}$, Chun Wei. A organização do conhecimento: Como as organizações usam a informação para criar significado, construir conhecimento e tomar decisões. $3^{\mathrm{a}}$ ed. São Paulo: Editora Senac, 2003. 415 p.

Conselho Nacional do Ministério Público. Metodologia De Gestão de Processos. 1ed. Goiânia, 2016.

DANTAS, Marcus Leal. SEGURANÇA DA INFORMAÇÃO: UMA ABORDAGEM FOCADA EM GESTÃO DE RISCOS. Pernambuco: Livro Rápido, 2011.

DAVENPORT, Thomas H. Ecologia da informação: POR QUE SÓ A TECNOLOGIA NÃO BASTA PARA O SUCESSO NA ERA DA INFORMAÇÃO. $6^{a}$ ed. São Paulo: Editora Futura, 1998. 316 p.

FALCÃO JÚNIOR, Marcos Antônio Gomes; SANTOS, Raimundo Nonato Macedo dos. A gestão de processos na análise das atividades de seleções públicas simplificadas: estudo de caso em uma prefeitura. Revista de Gestão e Tecnologia, Florianópolis, v. 6, n. 2, p. 1-14, 2016.

LIMA, Maria Alice Dias Da Silva; ALMEIDA, Maria Cecília Puntel De; LIMA, Cristiane Cauduro. A UTILIZAÇÃO DA OBSERVAÇÃO PARTICIPANTE E DA ENTREVISTA SEMI-ESTRUTURADA NA PESQUISA EM ENFERMAGEM. R. Gaúcha Enferm, Porto Alegre, v. 20, p. 1-13, sd.

MOREIRA, Maria José Belém Martins; MINGATTO, Karina; DRUKER, Marcel. BUSINESS PROCESS MANAGEMENT PLUG \& PLAY. Excelência em Gestão, Rio de Janeiro, p. 1-10, 2010.

PAIM, R. et al. O QUE SÃO BPMS: SISTEMAS DE SUPORTE ÀS TAREFAS PARA GESTÃO DE PROCESSOS. Centro Federal de Educação Tecnológica Celso Suckow da Fonseca, Rio de Janeiro, mai./ago. 2011.

PAVANI JUNIOR, Orlando. Mapeamento e gestão por processos - BPM: (Business Process Management). São Paulo: M. Books do Brasil, 2011. 376p., il. Inclui bibliografia. ISBN 9788576801030 (Broch.). 
REIS, Margarida Maria de Oliveira; BLATTMANN, Ursula. GESTÃO DE PROCESSOS EM BIBLIOTECAS. Revista Digital de Biblioteconomia e Ciência da Informação, Campinas, v. 1, n. 2, p. 1-17, 2004.

ROCHA, Eliana da Conceição; GOMES, Suely Henrique de A. Gestão da qualidade em unidades de informação. Ci. Inf., Brasília, maio/ago. 1993, p. 142-152.

ROZADOS, Helen Beatriz Frota. A informação científica e tecnológica e os serviços de informação. Inf. e Soc.: est., João Pessoa, jan./jun. 2006, v. 16 , n. 11 , p. $49-62$.

SILVA, Fabiano Couto Corrêa da; SCHONS, Claudio Henrique; RADOS, Gregório Jean Varvakis. A gestão de serviços em bibliotecas universitárias: proposta de modelo. Inf. Inf., Londrina, jul./dez. 2006, v. 11, n. 2.

SOUZA, Jacqueline De; KANTORSKI, Luciane Prado; LUIS, Margarita Antonia Villar. ANÁLISE DOCUMENTAL E OBSERVAÇÃO PARTICIPANTE NA PESQUISA EMSAÚDE MENTAL. Revista Baiana de Enfermagem, Salvador, v. 25, n. 2, p. 1-8, mai./ago. 2011.

Recebido em: 28/12/2018

Aceito em: 30/05/2019 